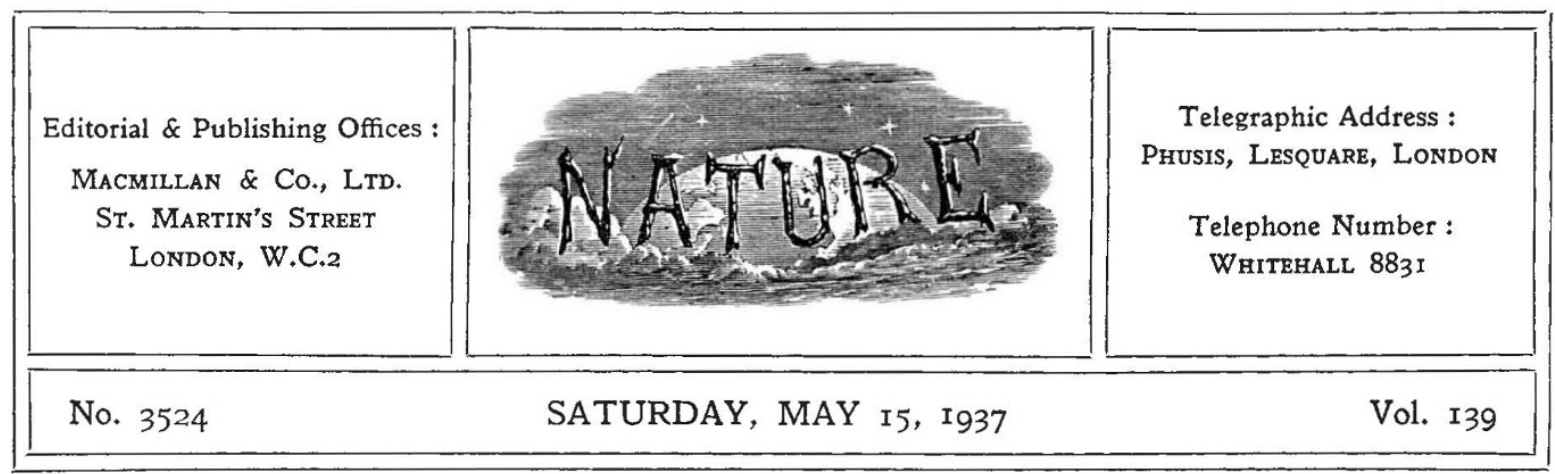

\title{
The National Food Supply
}

$\mathrm{I}^{\mathrm{T}}$ will be a source of gratification to those who believe that the problem of the nutrition of their populations is worthy of serious consideration by responsible Governments, to be reminded that in Great Britain the Ministry of Health and the Scottish Office are instigating searching inquiries into the food supply of the nation as a whole and into the distribution of specially desirable foods among different sections of the community. Two years ago, these Government Departments appointed an Advisory Committee on Nutrition which included some senior civil servants from various Ministries and Departments, and some prominent scientific workers in the field of nutrition such as Prof. E. P. Cathcart, of the University of Glasgow, Sir Frederick Gowland Hopkins, of the University of Cambridge, Prof. E. Mellanby, secretary of the Medical Research Council, and Sir John Orr, director of the Rowett Research Institution, Aberdeen. Its terms of reference were: "to inquire into the facts, quantitative and qualitative, in relation to the diet of the people, and to report as to any changes therein which appear desirable in the light of modern advances in the knowledge of nutrition".

The Committee has now issued its first report*. It has had before it estimates of the total food consumed in recent years by the population of the United Kingdom, and was thus able to compare the quantities of food available with the nutritional requirements suggested in the report by the Technical Commission of the League of Nations Health Organisation, which is reprinted as an appendix to the present report. This comparison does not pretend to give an exact picture of the existing state of affairs; nevertheless its results

* Ministry of Health. Advisory Committee on Nutrition. First Report. Pp. 52. (Iondon: H.M. Stationery Oftice, 1937.) 1s. 0d. net. are of considerable interest. It is calculated that the national food supply, after allowing a margin of 10 per cent for wastage, contains more than sufficient calories to meet the energy requirements of the population on the basis of the report of the League Commission. It is the opinion of the Advisory Committee, therefore, that all except a small fraction of the population are getting as many calories as they require. There is no deficiency of fat in the national food supply, though there is some deficiency in the diet of the very poorest. The total amount of protein available for the population is sufficient to supply its needs, but seeing that the proportion of animal protein in the diet increases as the standard of living rises with income, it is considered probable that there is some shortage of animal protein in the diets of the poorest section of the community.

The greatest discrepancy between the estimates of national consumption and the recommendations of the League Commission relates to liquid milk. The requirements on the basis of the League Commission's report are estimated to be equivalent to an allowance of seven-eighths of a pint daily per head of the population, whereas the present actual consumption in the United Kingdom is less than half this amount. Even if the consumption of condensed and dried milk is taken into account, the total quantity works out at only 60 per cent of the Commission's recommendation.

This deficiency is regarded with special concern and is referred to again and again in the present report. The Advisory Committee published in 1936 a memorandum on the nutritive value of milk which is republished as an appendix to this report. In it the opinion is expressed that the desirable amount of milk for children is from one 
to two pints a day, for expectant and nursing mothers about two pints a day and for other adult members of the community half a pint. The Committee deplores the fact that there is a deficiency of milk in the diet of large sections of the population at a time when there is a substantial surplus of liquid milk produced in the United Kingdom. The hope is expressed that the State will endeavour to ensure that a sufficient supply of safe milk will in the future be brought within the purchasing power of the poorest. It is considered that there is no other single measure which would do more to improve the health, development and resistance to disease of the rising generation than a largely increased consumption of safe milk by mothers, children and adolescents. While whole milk is a more complete food than other dairy products, the Committee would like to see skimmed milk and buttermilk more readily available for human consumption than they are at present.

With regard to other foods specially recommended by the League Commission, it has been possible in one or two instances to make comparisons between its recommendations and the actual consumption in the United Kingdom. The present average consumption of eggs is estimated to be 2.9 per head per week, while it is calculated that 3.9 per head per week would be necessary to satisfy the Commission's recommendation. The average weekly consumption of potatoes is in the region of 56 ounces per head; the Committee would like to see a larger consumption, to replace some of the sugar and highly milled cereal of the diet. It is pointed out that while sugar may be a useful source of energy, it possesses no other food value and, when taken in large amounts, it dulls the appetite for more valuable foods and may thus have an unfavourable effect on nutrition.

The recommendations which the Advisory Committee have made are based on experimental and medical data, which have already indicated the importance of good nutrition for the maintenance of health. It is admitted, however, that a great deal more information is necessary before a final verdict can be passed on the effect of good diets on the health of a community. The Committee has already proposed and instigated additional inquiries which should enable further practical suggestions to be made for improving the nutrition of the masses. It wishes, for example, to obtain a more reliable estimate than has hitherto been possible of the distribution of the population in income groups ; it has invited Government Departments to undertake dietary surveys on a comprehensive scale and has recommended specifically that exact studies of the diets of several hundred families should be carried out in England, Scotland and Wales; it has also recorded its view that efforts should be continued to establish a reliable group of tests for the assessment of the state of nutrition of individual human beings.

Viscount Astor directed attention in the House of Lords on May 5 to the Advisory Committee's report, and obtained a statement given on behalf of the Government by Viscount Gage. Lord Gage said that the Government accepted the conclusions of the Committee, but thought that much more information is desirable; and the Government is prepared to collect it. A threefold inquiry is proposed. The Ministry of Labour will make an inquiry in connexion with the cost of living index figure. For this it is hoped to secure the weekly budgets of 10,000 families taken over four separate weeks in various parts of Great Britain. These results will be checked by another inquiry, called a qualitative dietary survey, of a much more detailed character. This is already in progress, and will eventually embrace 500 families, of which 200 may be from Scotland. Then, from the last census figures, a definite proportion, say, one in 500 or one in 1,000 , of the family census schedules will be taken. Those are expected to show, roughly, after certain allowances are made for altered conditions, the distribution of the population according to occupation. These statisties will be compared with the information in the possession of the Ministry of Labour with regard to the wage rates current in such occupations. It is hoped that the statisticians will be able, on this basis, to correlate the results of these various inquiries and present a working analysis of how the incomes of the various classes of the community are divided with special reference to food.

What is not clear at the present moment is whether the Government only accepts the conclusions that the diet of the country is improving and that more data about this should be obtained, in which case a political gesture has been made to get over an embarrassing situation; or whether the main conclusions and recommendations have been accepted. If the Government has accepted these and intends to carry them out, then the new science of nutrition is about to be applied for the welfare of the people, and we are on the eve of what will be the greatest social reform of this century. 